\title{
Index of cardiac-electrophysiological balance and the effects of thrombolytic therapy on the electrocardiogram of patients with pulmonary embolism
}

\author{
(iD) Yakup Alsancak ${ }^{1}$ \\ (iD) Ahmet Taha Sahın' \\ Dhmet Seyfeddin Gurbuz ${ }^{1}$ \\ (iD) Ahmet Lutfi Sertdemir ${ }^{1}$ \\ (iD) Abdullah Icli ${ }^{1}$ \\ (iD) Hakan Akilli ${ }^{1}$ \\ (iD) Mehmet Akif Duzenli1
}

1. Necmettin Erbakan University, Meram Medical Faculty Department of Cardiology, Konya, Turkey.

http://dx.doi.org/10.1590/1806-9282.66.12.1657

\section{SUMMARY}

OBJECTIVE: Different parameters on electrocardiograms (ECG) have been investigated to predict arrhythmia and mortality in patients with acute pulmonary embolism (APE). The acute effect of thrombolytic therapy (TT) on these parameters has not been investigated yet.

METHODS: We examined the data of 83 patients who were evaluated as high-risk APE and discharged from the hospital after TT. First, the high-risk APE patients' ECGs were compared with healthy control subjects $(n=55)$. After their admission and 24 hours later, the ECGs of patients with APE were compared. Heart rate, P-wave morphology, QRS duration, QT distance, Tp-e, and the index of cardiac electrophysiological balance (iCEB) were analyzed.

RESULTS: Although P maximum was not different between the groups' ECGs, heart rate, QT, QTc (corrected QT) interval, Tp-e intervals, $T p$-e/QT ratio, and $P$ wave dispersion were significantly higher in the APE group ( $P$ values $<0.037$ ). iCEB or iCEBC (corrected iCEB) values were lower in APE group $(P<0.001)$. After TT, we determined a decrease in heart rate, Tp-e interval, and Tp-e/QT ratio $(P<0.001)$. Although we detected a decrease in the QT and QTc interval and QT dispersion (QTd), QTd had no statistical significance (respectively $P$-value 0.013, 0.029, and 0.096). The iCEB and ICEBc levels were lower after TT (P-value was 0.035 and 0.044 respectively).

CONCLUSION: The QT, QTc, Tp-e interval, Tp-e/QTc ratio, iCEB, and iCEBc values significantly decreased after TT. It may be thought that effective TT causes partial improvement in ventricular repolarization in an early period.

KEYWORDS: Electrocardiography. Pulmonary embolism. Thrombolytic therapy.

\section{INTRODUCTION}

Acute pulmonary embolism (APE) is still an important cause of cardiovascular mortality and morbidity. Therefore, the diagnosis should be made very quickly in suspicious clinical situations and treatment should be started. Since the condition may be asymptomatic, it has a wide range of clinical findings such as shortness of breath, chest pain, palpitations, syncope, and even sudden death, so diagnostic tests have a critical 
role in determining the presence or absence of APE. For this reason, computed tomographic pulmonary angiography, echocardiography, ventilation/perfusion scan (lung scintigraphy) and, rarely, pulmonary angiography are widely use to diagnoses ${ }^{1}$. However, it is not always possible to access adequate technical equipment or personnel; in this case, an old friend that is an easy-to-access, non-invasive, and inexpensive technique, i.e., the electrocardiography, attracts attention once again.

Despite many non-specific electrocardiographical (ECG) findings during pulmonary embolism, ST-segment depressions in several leads, complete or incomplete right bundle branch block (RBBB), T-wave inversion, and S1Q3T3 pattern are the bestknown changes ${ }^{2-4}$. In addition to these, some studies have investigated different parameters on surface ECG to predict arrhythmia and mortality in patients with APE over the last decade. QT-interval prolongation, which is a well-known ECG finding that is a marker for electrical instability and sudden cardiac death, was observed in patients with pulmonary embolism ${ }^{5}$. Also, a QTc (corrected QT) difference higher than 20 ms between $\mathrm{V} 1$ and $\mathrm{V} 6$ was shown to identify acute APE ${ }^{6}$. Moreover, QT dispersion (QTd), which demonstrates the difference in re-polarization, is significantly increased in patients with $\mathrm{APE}^{7}$. Another ECG parameter, P-wave dispersion, which is a marker of atrial depolarization heterogenity and known to predict the development of atrial fibrillation, was increased in patients with $\mathrm{APE}^{8}$. Novel pro-arrhythmogenic markers, the T-wave peak-toend (Tp-e) interval and Tp-e/QT ratio, which suggest transmural dispersion of the repolarization ventricle, were also increased in patients with $\mathrm{APE}^{5,9-11}$. More recently, the index of cardiac electrophysiological balance (iCEB), calculated by dividing the QT interval by the QRS duration, has been shown to be a predictor of ventricular arrhythmias, but its relationship with APE has not been investigated yet ${ }^{12,13}$.

When considering high-risk APE, improvement of these ECG changes may be observed when a treatment method (mechanical embolectomy, thrombolytic therapy, etc.) is applied, eliminating the thrombus and providing pulmonary blood flow. Therefore, the aim of the study was to investigate the relationship between the iCEB and diagnoses of APE and evaluate the status of ECG changes previously observed in patients with APE after thrombolytic therapy, which has never been investigated in the literature.

\section{METHODS}

\section{Study population and patient selection}

In this retrospective study, we analyzed patients who were older than 18 years and had been diagnosed with APE and received thrombolytic therapy in our university hospital department of cardiology between January 2017 and January 2020. Particularly, patients were included whose clinical diagnosis had been confirmed by computed tomography angiography. So, we obtained the data of 83 patients who were evaluated as high-risk APE and discharged from hospital after thrombolytic therapy.

Patient's ages, co-morbidities, hemodynamic conditions, and laboratory findings were recorded. The ECGs that had been obtained during the admission and 24 hours after the thrombolytic regimen were evaluated. Unsuitable or excessive noises in the ECGs, presence of documented atrial fibrillation or cardiac pacemaker rhythm, or left and right bundle branch block on the ECG; the presence of preexcitation syndromes; the presence of left ventricular hypertrophy criteria; known use of any drugs affecting the cardiac conduction system during admission, chronic renal failure (creatinine $>1.5 \mathrm{mg} / \mathrm{dl}$ ); the presence of electrolyte abnormalities; suspected active infection or malignancy during admission; chronic obstructive pulmonary diseases; and a history of percutaneous coronary intervention or coronary artery bypass surgery for coronary artery disease were accepted as the exclusion criteria for screened patients. When these exclusion criteria were applied to the study population, of the 22 patients excluded from the study, 6 had missing echocardiography or laboratory data and excessive "noise" in the ECG; 5 had a history of coronary artery disease (percutaneous coronary intervention $=3$, coronary artery bypass grafting $=2$ ); 3 had left or right branch bundle block; 4 had a chronic renal failure with increased creatinine levels; 4 had documented atrial fibrillation. Eventually, 61 patients' pre- and post-treatment records were evaluated. In addition, 55 healthy control subjects were enrolled in the study to investigate the effect of massive APE on surface ECG. So, a total of 116 patients' data were analyzed. The flowchart of the study design is shown in Figure 1.

The study was approved by the Institutional Review Board and was conducted in accordance with the Helsinki declaration. The study was approved by the local Ethics Committee of our faculty under 13.09.2019/93/2048 ID number. 
A total of 83 pulmonary embolism patients who received thrombolytic

$$
\text { therapy from the hospital database were identified. }
$$

22 patients were excluded from the study.

\section{6 patients' ECG data were compared to determine the effects of pulmonary embolism on ECG.}

122 ECG were examined.

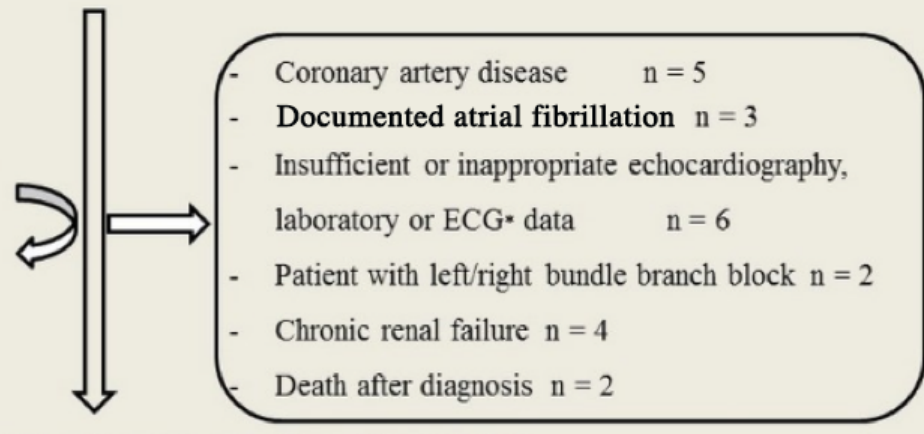

Coronary artery disease $\quad n=5$

Documented atrial fibrillation $\mathrm{n}=3$

Insufficient or inappropriate echocardiography,

laboratory or ECG* data $\quad \mathrm{n}=6$

Patient with left/right bundle branch block $n=2$

Chronic renal failure $\mathrm{n}=4$

Death after diagnosis $n=2$

A total of 61 patients with pulmonary embolism were included.
FIGURE 1.

FLOWCHART

OF THE STUDY

DESIGN

Finally, 177 ECG were analyzed.

55 healthy subjects were included.

The initial ECG during admission and the ECGs

24 hours after thrombolytic therapy were compared.

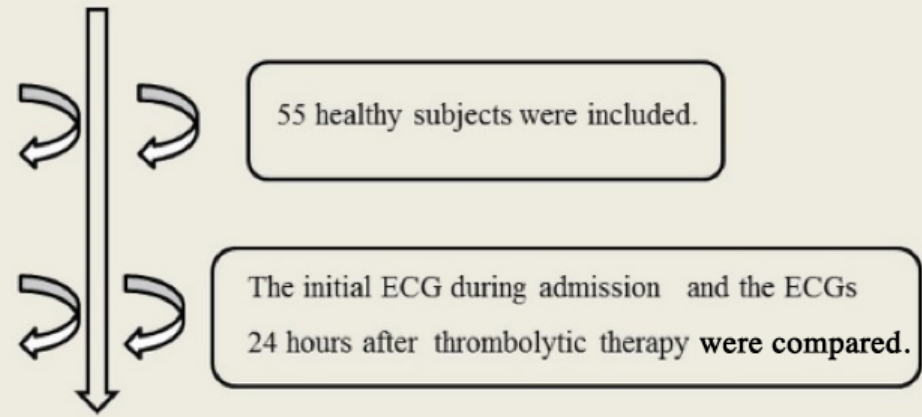

*ECG: electrocardiogran

\section{Electrocardiographic examinations}

Heart rate, P-wave morphology, QRS duration, QT distance, Tp-e, and iCEB were analyzed. All ECG samples were examined on a digital platform and measurements were then taken using special software (Adobe Photoshop) to provide necessary magnification. An average value of three measurements was taken for each lead.

The beginning point of the P-wave was described as the first upward positive or downward negative deflection between the isoelectric line, and the end of the P-wave was characterized as the point where the last deflection of the P-wave met the isoelectric line. Maximum $\left(\mathrm{P}_{\max }\right)$ and minimum $\mathrm{P}\left(\mathrm{P}_{\text {min }}\right)$ wave durations were recorded. $\mathrm{P}$-wave dispersion (PWD) was defined as the difference between the maximum and minimum P-wave durations ${ }^{14}$. The QT interval was conventionally obtained by manually measuring from the onset of the QRS complex to the crossing point of the $T$ wave and isoelectric line. The heart-rate-corrected QT interval was calculated using Bazett's formula [cQT = QT $\sqrt{ }(\mathrm{R}-\mathrm{R}$ interval)]. QT dispersion (QTd) was obtained by measuring the longest QT interval $\left(\mathrm{QT}_{\max }\right)$ and the shortest QT interval $\left(\mathrm{QT}_{\min }\right)$ in any lead ${ }^{15}$. QT interval measurements were taken by examining recordings from leads D2 and precordial V5, and the longer lead was recorded for statistical analysis. ${ }^{16}$ The distance from the peak of the T-wave $\left(\mathrm{T}_{\text {peak }}\right)$ to the endpoint of the T-wave ( $\mathrm{T}$ end) ( $\mathrm{T}_{\text {peak-end }}$ or Tp-e) was obtained from the chest leads. The Tp-e/QT ratio was obtained by dividing the Tp-e duration by the QT interval in the precordial V5 lead ${ }^{16,17}$. The index of cardiac electrophysiological balance (iCEB) was obtained by dividing the QT interval by the QRS duration in the same lead (D2 or $\mathrm{V} 5)^{12,13}$. The iCEBc was accepted as QTc/QRS ratio.

\section{Statistical Analysis}

SPSS $^{\circledR}$ version 16.0 statistical package software (SPSS Inc., Chicago, IL, United States) was used for statistical analyses. Descriptive statistics were shown as mean \pm standard deviation or median (interquartile range) for continuous variables, and nominal variables were shown as the number of cases (n) and percentages (\%). The normality of distribution was evaluated using the Kolmogorov-Smirnov test. Mean values of continuous variables were compared between independent groups using the Student's T-test, one-way ANOVA test, or Kruskal-Wallis test as appropriate. The chi-square test was performed to compare the study groups in terms of categorical variables. The pre-treatment and post-treatment echocardiographic and ECG 
parameters of patients with APE were compared with paired t-tests or $K$-related sample tests. A p-value below 0.05 was considered statistically significant.

\section{RESULTS}

A total of 116 patients with a mean age of 63.13 [11.95] years, 83 (71.6\%) of whom were women, formed the study population. There were no statistically significant differences between the groups in terms of gender, age, diabetes mellitus, hypertension, and smoking status $(P>0.05)$. Biochemical and hematological laboratory parameters were similar except for white blood count, serum glutamic oxaloacetic transaminase (SGOT), serum glutamate-pyruvate transaminase (SGPT), calcium, and high-density lipoprotein cholesterol. White blood count, SGOT, SGPT levels were higher in the APE group $(P<0.045)$, and troponin levels were found to be high in patients with APE, as expected. In computed tomographical findings of the APE group, $83 \%$ of the patients had a thrombus located in the main and lobar pulmonary arteries, $17 \%$ had a thrombus seen in the subsegmental branches. The study groups were comparable in terms of echocardiographic and ECG parameters. Accordingly, in patients with APE, pulmonary artery pressure, and left ventricular end-diastolic and systolic diameter were higher than in the control group $(P=0.001, P=0.022$, and $P=0.023$, respectively). Moreover, the left atrial size and left ventricle ejection fraction were similar between groups. Although P maximum was not different between the groups on ECG, the heart rate, QT, QTc interval, Tp-e intervals, Tp-e/QT ratio, and PWD were significantly higher in the APE group ( $P$ values $<0.031)$. Also, iCEB or iCEBc values were lower in the APE group $(P<0.001)$. The demographic features, laboratory parameters, electrocardiographic and echocardiographic characteristics, and comparison between the groups are summarized in Tables 1 and 2.

In the analysis conducted to assess the effect of thrombolytic therapy, based on the echocardiographic evaluation, we detected only that the pulmonary artery pressure was significantly decreased (56.73 [13.31] mmHg to 41.64 [12.24] $\mathrm{mmHg}$ ) after thrombolytic therapy, as expected $(P=0.001)$. We detected that the systolic blood pressure of patients with APE increased from 84.08 [12.35] to 111.04 [13.62] $\mathrm{mmHg}$ and diastolic blood pressures from 53.89 [15.11] to 68.12 [14.45] mmHg after 24 hours $(P<0.001)$. Furthermore, we determined a significant decrease in heart rate, Tp-e interval, and Tp-e/QT ratio $(P<0.001)$. Although we detected a decrease of the QT, QTc interval, and QTd, QTd had no statistical significance (respectively, P-value 0.013, 0.029, and 0.096). In addition, the iCEB and iCEBc levels were lower after thrombolytic therapy ( $P$-value 0.035 and 0.044 respectively). Table 3 and Figure 2 demonstrate the changes in ECG parameters after the treatment.

FIGURE 2. CHANGES IN ELECTROCARDIOGRAPHIC PARAMETERS AFTER THE TREATMENT

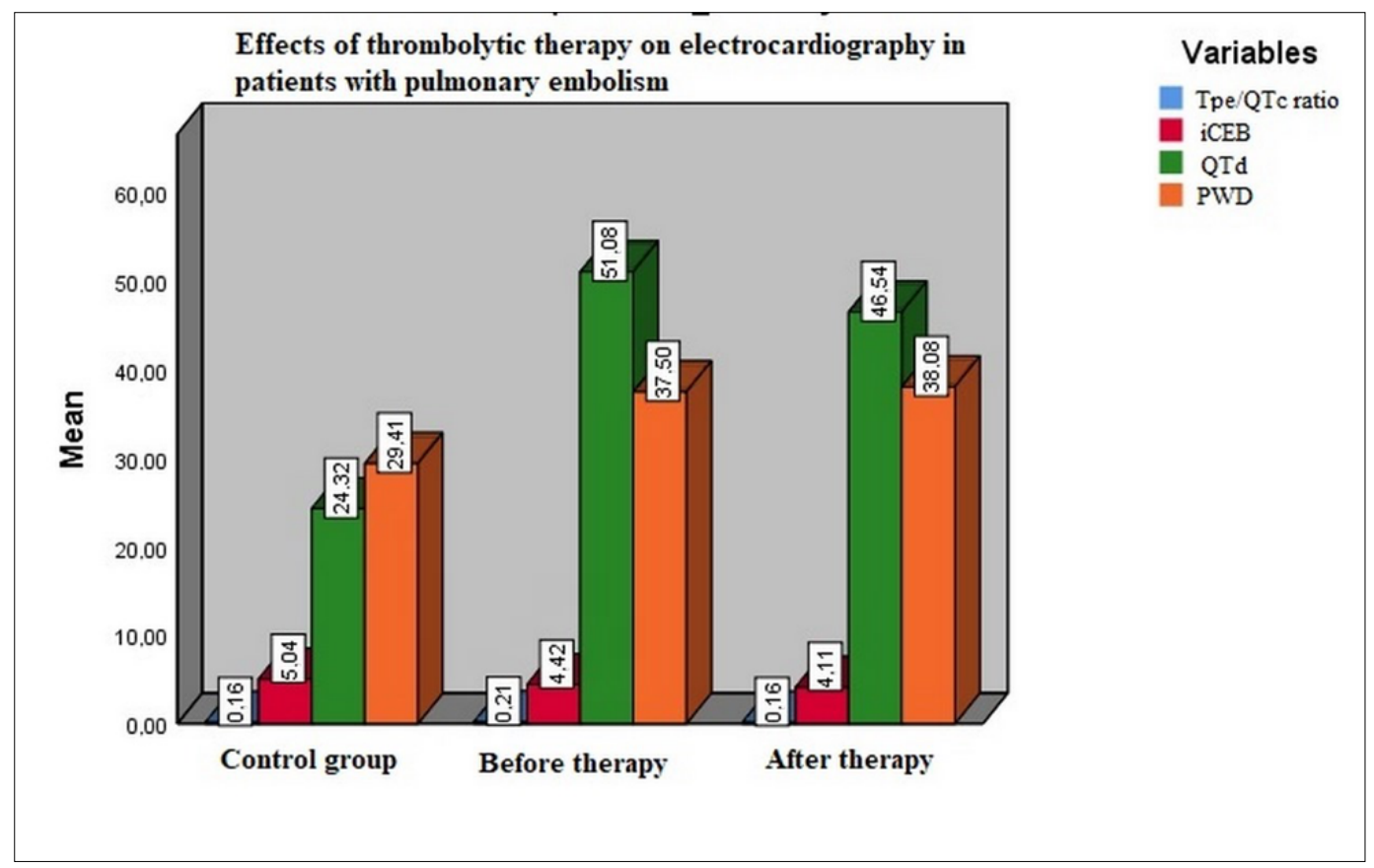


TABLE 1. BASAL CHARACTERISTICS, LABORATORY AND ECHOCARDIOGRAPHICAL FEATURES OF THE STUDY POPULATION

\begin{tabular}{|c|c|c|c|}
\hline Variables & $\begin{array}{l}\text { Control group } \\
(n=55)\end{array}$ & $\begin{array}{l}\text { Patients with pulmonary } \\
\text { embolism } \\
(n=61)\end{array}$ & P-value \\
\hline \multicolumn{4}{|l|}{ Demographic characteristics } \\
\hline Age (years, mean \pm std) & $61.67 \pm 8.82$ & $64.4 \pm 14.16$ & 0.214 \\
\hline Gender (female, n/\%) & $42(76)$ & $41(67)$ & 0.275 \\
\hline Diabetes mellitus (n/\%) & $18(33)$ & $13(22)$ & 0.165 \\
\hline Hypertension (n/\%) & $22(40)$ & $28(46)$ & 0.109 \\
\hline Smoking ( $\mathrm{n} / \%)$ & $9(16)$ & $16(26)$ & 0.061 \\
\hline \multicolumn{4}{|l|}{ Laboratory parameters } \\
\hline Hemoglobin (g/dL, mean \pm std) & $13.25 \pm 3.35$ & $12.73 \pm 2.04$ & 0.312 \\
\hline WBC (103/ uL, mean \pm std) & $7.88 \pm 1.66$ & $11.35 \pm 4.26$ & 0.001 \\
\hline Platelet (103/ uL, mean \pm std) & $268 \pm 78.29$ & $257 \pm 117$ & 0.573 \\
\hline Creatinine (mg/dL, mean \pm std) & $0.78 \pm 0.19$ & $0.84 \pm 0.23$ & 0.114 \\
\hline Potassium (mmol/L, mean \pm std) & $4.48 \pm 0.57$ & $4.49 \pm 0.56$ & 0.978 \\
\hline SGOT (U/L, median, IQR) & $22.33(18-29)$ & $63.93(24-65)$ & 0.011 \\
\hline SGPT (U/L, median, IQR) & $20.35(16-40)$ & $48.56(35-75)$ & 0.029 \\
\hline Calcium (mg/dL, mean \pm std) & $9.03 \pm 1.54$ & $8.52 \pm 0.75$ & 0.045 \\
\hline Magnesium (mg/dL, mean \pm std) & $1.86 \pm 0.17$ & $2.16 \pm 1.26$ & 0.085 \\
\hline LDL (mg/dL, meanıstd) & $123 \pm 36.93$ & $108 \pm 20.24$ & 0.124 \\
\hline HDL (mg/dL, mean \pm std) & $47.5 \pm 12.9$ & $35.38 \pm 15.83$ & 0.005 \\
\hline Triglycerides (mg/dL, mean \pm std) & $149 \pm 80.11$ & $146 \pm 92.71$ & 0.860 \\
\hline Troponin (ng/mL, meanะstd) & - & $3.22 \pm 2.07$ & - \\
\hline \multicolumn{4}{|l|}{ Echocardiographic features } \\
\hline LVEDD (cm, mean \pm std) & $4.19 \pm 2.48$ & $4.41 \pm 0.52$ & 0.022 \\
\hline LVESD (cm, mean \pm std) & $2.42 \pm 1.82$ & $2.68 \pm 0.49$ & 0.023 \\
\hline Ejection fraction (\%,mean \pm std) & $54.72 \pm 7.4$ & $55.78 \pm 4.84$ & 0.359 \\
\hline Left atrial size (cm, mean \pm std) & $2.61 \pm 2.02$ & $4.41 \pm 2.25$ & 0.076 \\
\hline PAB (mmHg, mean $\pm s t d)$ & $29.12 \pm 4.37$ & $56.73 \pm 13.31$ & 0.001 \\
\hline
\end{tabular}

*HDL: high-density lipoprotein cholesterol; LVEDD: left ventricular end-diastolic diameter; LVESD: left ventricular end-systolic diameter; SGOT: serum glutamic oxaloacetic transaminase; SGPT: serum glutamic pyruvic transaminase; LDL: low-density lipoprotein cholesterol; PAB: pulmonary artery pressure; WBC: white blood cell count.

TABLE 2. ELECTROCARDIOGRAPHIC COMPARISON BETWEEN PULMONARY EMBOLISM AND THE CONTROL GROUP

\begin{tabular}{|c|c|c|c|}
\hline $\begin{array}{l}\text { Variables } \\
\text { (mean } \pm \text { std) }\end{array}$ & $\begin{array}{l}\text { Control group } \\
(n=55)\end{array}$ & $\begin{array}{l}\text { Patients with pulmonary } \\
\text { embolism } \\
(n=61)\end{array}$ & P-value \\
\hline Heart rate (pulse/min) & $71.96 \pm 12.09$ & $114.59 \pm 17.5$ & 0.001 \\
\hline P maximum (msn) & $79.61 \pm 25.75$ & $77.83 \pm 15.98$ & 0.665 \\
\hline$P$ minimum (msn) & $50.18 \pm 19.62$ & $40.32 \pm 12.51$ & 0.002 \\
\hline PWD (msn) & $29.41 \pm 14.01$ & $37.5 \pm 14.49$ & 0.003 \\
\hline QRS interval (msn) & $68.23 \pm 21.91$ & $87.86 \pm 17.23$ & 0.001 \\
\hline QT interval (msn) & $343.87 \pm 57.7$ & $386.52 \pm 39.88$ & 0.041 \\
\hline QTc interval (msn) & $383.96 \pm 39.44$ & $424.39 \pm 44.1$ & 0.031 \\
\hline QTd (msn, mean (std) & $24.32 \pm 16.72$ & $51.08 \pm 20.75$ & 0.001 \\
\hline QT/QRS ratio (ICEB) & $5.04 \pm 1.51$ & $4.42 \pm 0.82$ & 0.011 \\
\hline QTc/QRS ratio (c-iCEB) & $5.63 \pm 2.19$ & $4.85 \pm 0.85$ & 0.001 \\
\hline Tp-e interval (msn) & $54.36 \pm 14.46$ & $80.49 \pm 19.18$ & 0.001 \\
\hline Tp-e/QT ratio & $0.16 \pm 0.04$ & $0.21 \pm 0.05$ & 0.001 \\
\hline Tp-e/cQT ratio & $0.13 \pm 0.03$ & $0.18 \pm 0.04$ & 0.001 \\
\hline
\end{tabular}

*PWD: P-wave dispersion; QTd: QT dispersion; QTc: corrected QT interval; Tp-e: T peak to end interval. *Data are presented as mean (standard deviation). 
TABLE 3. COMPARISON OF ELECTROCARDIOGRAPHIC PARAMETERS BEFORE AND AFTER THROMBOLYTIC THERAPY

\begin{tabular}{l|l|l|l}
$\begin{array}{l}\text { Variables } \\
\text { (mean } \pm \text { std) }\end{array}$ & $\begin{array}{l}\text { Before thrombolytic } \\
\text { therapy }\end{array}$ & $\begin{array}{l}\text { After thrombolytic } \\
\text { therapy }\end{array}$ & P-value \\
\hline Heart rate (pulse/min) & $114.59 \pm 17.5$ & $90.98 \pm 19.62$ & 0.001 \\
\hline P maximum (msn) & $77.83 \pm 15.98$ & $75.73 \pm 16.47$ & 0.423 \\
\hline P minimum (msn) & $40.32 \pm 12.51$ & $37.21 \pm 9.68$ & 0.097 \\
\hline PWD (msn) & $37.5 \pm 14.49$ & $38.08 \pm 15.24$ & 0.837 \\
\hline QRS interval (msn) & $87.86 \pm 17.23$ & $85.55 \pm 13.13$ & 0.217 \\
\hline QT interval (msn) & $386.52 \pm 39.88$ & $346.59 \pm 48.56$ & 0.013 \\
\hline QTc interval (msn) & $424.39 \pm 44.1$ & $410.89 \pm 49.87$ & 0.029 \\
\hline QTd (msn) & $51.08 \pm 20.75$ & $46.54 \pm 19.15$ & 0.096 \\
\hline QT/QRS ratio (iCEB) & $4.42 \pm 0.82$ & $4.11 \pm 0.83$ & 0.035 \\
\hline QTc/QRS ratio (iCEBc) & $4.85 \pm 0.85$ & $4.62 \pm 0.94$ & 0.044 \\
\hline Tp-e interval (msn) & $80.49 \pm 19.18$ & $57.29 \pm 20.07$ \\
\hline Tp-e/QT ratio & $0.21 \pm 0.05$ & $0.16 \pm 0.05$ & 0.001 \\
\hline Tp-e/cQT ratio & $0.18 \pm 0.04$ & $0.13 \pm 0.04$ & 0.001 \\
\hline
\end{tabular}

*PWD: P-wave dispersion; QTd: QT dispersion; QTc: corrected QT interval; Tpe: T peak to end interval. *Data are presented as mean (standard deviation)

\section{DISCUSSION}

In the current study, our results indicate that PWD, QT, QTc, Tp-e intervals, and Tp-e/QT ratio on standard 12-lead surface ECG were higher in patients with APE. Moreover, the results of this study demonstrate that the index of cardiac electrophysiological balance (iCEB) was lower in this group of patients. Besides these findings, QT, QTc, Tp-e interval, Tp-e/QT ratio, and iCEB value showed significant decreases after thrombolytic therapy. We could not detect a significant change in QTd and PWD after the treatment.

Many ECG patterns that can be observed during APE have been described in detail, even an ECG scoring system has been developed to identify highrisk patients. Daniel et al. ${ }^{18}$ developed a score using S1Q3T3, RBBB, T-wave inversion, and tachycardia on ECG, and they speculated that a higher score indicates severe pulmonary hypertension. Also, it was shown that scores may be a basic risk stratification tool for patients with acute $\mathrm{PE}^{19}$. Furthermore, the TwiST score (tachycardia, S-wave in lead I, and TWI in leads V1 through V3), which is a prognostic finding for adverse clinical events in APE, was suggested by Hariharan et al. ${ }^{20}$. In addition to these scoring systems, by adding different ECG findings (atrial fibrillation or ST elevation in AVR or Qr in lead V1, or right axis deviation, or P pulmonale), there have been attempts to demonstrate the relationship between APE and $\mathrm{ECG}^{21,22}$. However, there is a reality that must be noted: only $70 \%$ of patients with APE have abnormal ECG recordings ${ }^{23}$.

The relationship between different ECG signs and APE still draws attention due to the wide range of findings on ECG. In this context, ECG repolarization markers have also been associated with APE. Although the underlying pathophysiology is not yet clear for this condition, several mechanisms have been suggested. Right ventricular enlargement and acute cor pulmonale due to rapid ventricular pressure overload, impairment of coronary and left ventricle perfusion, and reduced cardiac out-put due to right ventricle damage, increasing right ventricle wall tension and neurohumoral activity and, eventually, myocardial ischemia may be accepted as major causes of this situation ${ }^{4,19,24,25}$. Tp-e and Tp-e/QT ratio are thought to be pro-arrhythmogenic markers, which give an idea about transmural dispersion of left ventricular (LV) repolarization ${ }^{9,10}$. Icli et al. ${ }^{5}$ demonstrated that prolonged cTp-e is a useful marker in early risk stratification and hospital mortality in patients with acute PE. In ours and another study, we also detected a higher Tp-e interval in patients with APE than in the control groups ${ }^{11}$. In addition, we showed a higher QTd, Tp-e/QT, and Tp-e/QTc ratio in high-risk APE. Unlike other studies, we found a significant reduction in Tp-e, Tp-e/QT, QT, QTc intervals after thrombolytic therapy in a short period. Although QTd values tend to decrease after the treatment, they could not 
reach statistical significance. QTd may be expected to decrease in a longer follow-up period. The index of cardiac electrophysiological balance (iCEB), estimated as the QT interval divided by the QRS duration, is a novel risk indicator for predicting malignant ventricular arrhythmias ${ }^{12}$. It has been demonstrated that the iCEB is equal to the cardiac wavelength $\lambda(\lambda=$ effective refractory period (ERP) $\mathrm{x}$ conduction velocity) and that an increased or decreased ratio of iCEB might potentially predict TdP or non-TdP mediated VT/VF, respectively. Authors have speculated that iCEB may reflect both of the depolarization and repolarization phases of the cardiac action potential ${ }^{12,13}$. There are limited data about iCEB according to the literature. Sivri et al. ${ }^{26}$ demonstrated elevated iCEB levels after hemodialysis that indicate an increased risk of TdP-mediated ventricular arrhythmia. In another study, no significant relationship between the iCEB and the degree of coronary collateral circulation in patients with chronic total occlusion was shown27. In this study, we observed that the ICEB and iCEBc values were lower in patients with APE compared to the healthy controls. So, decreased levels of iCEB may predict non-torsades de pointes mediated ventricular arrhythmia in patients with acute APE. We found that the downward trend of the $\mathrm{iCEB} / \mathrm{iCEBc}$ values continued significantly after thrombolytic therapy, unlike other ventricular arrhythmia indicators. Despite the significant decrease in the QT interval, the iCEB or iCEBc values were observed to be lower after the therapy due to the absence of a considerable narrowing in the QRS interval. Perhaps, these results may have emerged due to our strict exclusion criteria. If patients with QRS $>120$ msn had been included in the study, our results might have been different for the iCEB. We think that a longer follow-up period is needed to provide more information about the iCEB. According to these results, we may conclude that effective thrombolytic therapy causes partial improvement in ventricular repolarization in the early period. Regarding the atrial status, we detected a higher PWD in patients with APE, but we could not demonstrate an improvement after thrombolytic therapy. PWD, which is known to predict the development of atrial fibrillation, also relatively reflects the abnormalities of atrial enlargement and structure $^{14,28}$. Elevated right ventricle end-diastolic pressure and acute tricuspid valve insufficiency are the main causes of increasing right-atrial pressure and atrial-wall tension. Since the right atrium has an anatomically thinner structure, it may take a long time to return to the normal dimensions after acute enlargement. Therefore, improvement in the PWD value may not be observed after thrombolytic therapy in a short follow up period. Finally, hypocalcemia is a frequent occurrence in patients with APE, such as our study population, and it may cause ECG changes during APE and malignant arrhythmias ${ }^{29}$. We need further studies on this subject.

\section{Limitations}

Our study has a few limitations. Firstly, this is a single-center, retrospective study with a low number of participants. Secondly, the patients were not followed up for malignant ventricular arrhythmia, sudden cardiac death, and their ECG changes. Thirdly, the lack of 24-hour electrocardiographic Holter monitoring to detect arrhythmic conditions in these patients may be considered as a limitation. Although we excluded patients who were known to be using any drugs affecting the cardiac conduction system during admission, the lack of data on patients receiving beta-blockers, non-dihydropyridine calcium channel blockers or digital, and antibiotics with known efficacy on electrocardiography (erythromycin, azithromycin, etc.) may also be considered a limitation. Finally, we think that the absence of mortality analysis by ECG changes may be considered the main limitation because patients who died after thrombolytic therapy were not included in the study.

\section{CONCLUSION}

To the best of our knowledge, there is no study investigating the effects of thrombolytic therapy on ECG parameters and iCEB in high-risk APE in the literature. In our study, we observed higher QTc, Tp-e, Tp-e/QTc, PWD interval, and lower iCEB, iCEBc values in patients with acute pulmonary embolism compared to healthy subjects. Besides these findings, we demonstrated that QT, QTc, Tp-e interval, Tp-e/QTc ratio, and iCEB/iCEBc values showed significant decreases after thrombolytic therapy. According to these results, we may conclude that effective thrombolytic therapy causes partial improvement in ventricular repolarization in the early period. Larger studies on this subject are needed to confirm our results.

\section{Funding}

None 


\section{Author's Contribution}

Concept/design: Y.A, A.T.S, A.S.G, A.L.S, A.İ, H.A, M.A.D; Data analysis/interpretation: Y.A, A.T.S, A.S.G, A.L.S; Drafting of the article: Y.A, A.T.S, A.S.G, A.L.S;
Critical revision of the article: Y.A, A.İ, H.A, M.A.D; Approval of the article: Y.A, A.S.G, M.A.D; Statistics: Y.A, ASG with a professional of statistical analysis; Data collection: Y.A, A.T.S, A.L.S.

\section{RESUMO}

OBJETIVO: Diferentes parâmetros de eletrocardiograma (ECG) têm sido investigados para predizer mortalidade e arritmia em pacientes com embolia pulmonar aguda (EPA). O efeito agudo da terapia trombolítica (TT) nesses parâmetros ainda não foi investigado.

MÉTODOs: Examinamos os dados de 83 pacientes avaliados com EPA de alto risco e que receberam alta hospitalar após TT. Primeiramente, comparamos os ECGs dos pacientes com EPA de alto risco com os de indivíduos saudáveis $(n=55)$. Os ECGs dos pacientes com EPA foram comparados logo após a internação e 24 horas mais tarde. A frequência cardíaca, a morfologia da onda $P$, a duração do QRS, o intervalo QT, Tp-e e o índice de equilíbrio eletrofisiológico cardíaco (iCEB) foram analisados.

RESULTADOS: Embora o valor máximo de P não tenha sido diferente entre os grupos no ECG, a frequência cardíaca, QT, intervalo QTC (QT corrigido), intervalos Tpe, razão TP-e/QT e dispersão da onda P foram significativamente mais elevados no grupo de EPA (valores de $P<0,031)$. Os valores do iCEB ou iCEBc (iCEB corrigido) foram inferiores no grupo de APE $(P<0,001)$. Após a TT, observamos uma diminuição da frequência cardíaca, do intervalo TP-e e da razão TP-e/QT ( $P<0,001)$. Apesar de termos observado uma diminuição do intervalo QT e QTc e da dispersão do QT (QTd), o valor de QTd não apresentou uma diferença estatisticamente significativa (respectivamente, valor de P 0,013, 0,029 e 0,096). Os níveis do iCEB e iCEBc foram menores após a TT (valor de P 0,035 e 0,044, respectivamente).

CONCLUSÃo: Os valores de QT, QTc, intervalo Tp-e, razão Tp-e/QTc, iCEB e iCEBc diminuíram significativamente após TT. Pode-se concluir que a TT eficaz causa uma melhora parcial da repolarização ventricular no período inicial.

PALAVRAS-CHAVE: Eletrocardiografia. Embolia pulmonar. Terapia trombolítica.

\section{REFERENCES}

1. Konstantinides SV, Meyer G, Becattini C, Bueno H, Geersing G), Harjola VP, et al; The Task Force for the diagnosis and management of acute pulmonary embolism of the European Society of Cardiology (ESC). 2019 ESC Guidelines for the diagnosis and management of acute pulmonary embolism developed in collaboration with the European Respiratory Society (ERS): The Task Force for the diagnosis and management of acute pulmonary embolism of the European Society of Cardiology (ESC). Eur Respir J. 2019;54(3):1901647.

2. Geibel A, Zehender M, Kasper W, Olschewski M, Klima C, Konstantinides SV. Prognostic value of the ECG on admission in patients with acute major pulmonary embolism. Eur Respir ). 2005;25(5):843-8.

3. Punukollu G, Gowda RM, Vasavada BC, Khan IA. Role of electrocardiography in identifying right ventricular dysfunction in acute pulmonary embolism. Am J Cardiol. 2005;96(3):450-2.

4. Kosuge M, Ebina T, Hibi K, Tsukahara K, Iwahashi N, Umemura S, et al. Differences in negative $T$ waves between acute pulmonary embolism and acute coronary syndrome. Circ J. 2014;78(2):483-9.

5. Icli A, Kayrak M, Akilli H, Aribas A, Coskun M, Ozer SF, et al. Prognostic value of Tpeak-Tend interval in patients with acute pulmonary embolism. BMC Cardiovascular Disorders. 2015;15:99.

6. Park SJ, Kwon CH, Bae BJ, Kim BS, Kim SH, Kim HJ, et al. Diagnostic value of the corrected QT difference between leads V1 and V6 in patients with acute pulmonary thromboembolism. Medicine (Baltimore). 2017;96(43):e8430.

7. Ermis N, Ermis H, Sen N, Kepez A, Cuglan B. QT dispersion in patients with pulmonary embolism. Wien Klin Wochenschr. 2010;122(23-24):691-7.

8. Akgüllü Ç, Eryılmaz U, Dağtekin $E$, Akdeniz $M$, Güngör $H$, Zencir $C$, et al. Usefullness of P-wave and QT dispersions for predicting early death in patients with acute pulmonary embolism. ADU Tip Fak Derg. 2014;15(3):105-9.

9. Hetland M, Haugaa KH, Sarvari SI, Erikssen G, Kongsgaard E, Edvardsen T. A novel ECG-index for prediction of ventricular arrhythmias in patients after myocardial infarction. Ann Noninvasive Electrocardiol. 2014;19(4):330-7.

10. Gupta P, Patel C, Patel H, Narayanaswamy S, Malhotra B, Green JT, et al. T(p-e)/QT ratio as an index of arrhythmogenesis. J Electrocardiol. 2008;41(6):567-74
11. Onur ST, Emet S, Surmen S, Kara K, Kose M, Oflaz H, et al. A novel parameter for the diagnosis of acute pulmonary embolism: the T-wave peak-to-end interval. Eur Rev Med Pharmacol Sci. 2016;20(8):1566-70.

12. Lu HR, Yan GX, Gallacher DJ. A new biomarker - index of cardiac electrophysiological balance (iCEB) - plays an important role in drug-induced cardiac arrhythmias: beyond QT-prolongation and Torsades de Pointes (TdPs). J Pharmacol Toxicol Methods. 2013;68(2):250-9.

13. Robyns T, Lu HR, Gallacher DJ, Garweg C, Ector J, Willems R, et al. Evaluation of Index of Cardio-Electrophysiological Balance (iCEB) as a new biomarker for the identification of patients at increased arrhythmic risk. Ann Noninvasive Electrocardiol. 2016;21(3):294-304.

14. Dilaveris PE, Gialafos EJ, Sideris SK, Theopistou AM, Andrikopoulos GK, Kyriakidis $M$, et al. Simple electrocardiographic markers for the prediction of paroxysmal idiopathic atrial fibrillation. Am Heart ). 1998;135(5 Pt 1):733-8.

15. Malik M, Batchvarov VN. Measurement, interpretation and clinical potential of QT dispersion. J Am Coll Cardiol. 2000;36(6):1749-66.

16. Shimizu M, Ino H, Okeie K, Yamaguchi M, Nagata M, Hayashi K, et al. T-peak to T-end interval may be a better predictor of high-risk patients with hypertrophic cardiomyopathy associated with a cardiac troponin I mutation than QT dispersion. Clin Cardiol. 2002;25(7):335-9.

17. Castro Hevia |, Antzelevitch C, Tornés Bárzaga F, Dorantes Sánchez M, Dorticós Balea F, Zayas Molina R, et al. Tpeak-Tend and Tpeak-Tend dispersion as risk factors for ventricular tachycardia/ventricular fibrillation in patients with the Brugada syndrome. J Am Coll Cardiol. 2006;47(9):1828-34.

18. Daniel KR, Courtney DM, Kline JA. Assessment of cardiac stress from massive pulmonary embolism with 12-lead ECG. Chest. 2001;120(2):474-81.

19. Ryu HM, Lee JH, Kwon YS, Lee SH, Bae MH, Lee JH, et al. Electrocardiography patterns and the role of the electrocardiography score for risk stratification in acute pulmonary embolism. Korean Circ J. 2010;40(10):499-506.

20. Hariharan P, Dudzinski DM, Okechukwu I, Takayesu IK, Chang Y, Kabrhel C. Association between electrocardiographic findings, right heart strain, and short-term adverse clinical events in patients with acute pulmonary embolism. Clin Cardiol. 2015;38(4):236-42. 
21. Qaddoura A, Digby GC, Kabali C, Kukla P, Zhan ZQ, Baranchuk AM. The value of electrocardiography in prognosticating clinical deterioration and mortality in acute pulmonary embolism: a systematic review and meta-analysis. Clin Cardiol. 2017;40(10):814-24.

22. Shopp JD, Stewart LK, Emmett TW, Kline JA. Findings from 12-lead electrocardiography that predict circulatory shock from pulmonary embolism: systematic review and meta-analysis. Acad Emerg Med. 2015;22(10):1127-37.

23. Cheng AS, Money-Kyrle A. Instructive ECG series in massive bilateral pulmonary embolism. Heart. 2005;91(7):860-2.

24. Abecasis J, Monge J, Alberca D, Grenho MF, Arroja I, Aleixo AM, et al. Electrocardiographic presentation of massive and submassive pulmonary embolism. Rev Port Cardiol. 2008;27(5):591-610.

25. Tverskaya MS, Karpova VV, Virganskii AO, Klyuchikov VY, Sukhoparova WV, Zherikova NS. Structural and metabolic changes in cardiac conducting system during massive pulmonary embolism. Bull Exp Biol Med. 2000;130(10):940-4.

26. Sivri S, Çelik M. Evaluation of index of cardiac-electrophysiological balance before and after hemodialysis in patients with end-stage renal disease. J Electrocardiol. 2019;54:72-5

27. Alsancak Y, Gurbuz AS, Sakli B, Icli A. Relation between index of cardio-electrophysiological balance and Tp-e/QT ratio and collateral circulation. Selcuk Med J. 2019;35(3):169-75.

28. Hashemi Jazi M, Amirpour A, Zavvar R, Behjati M, Gharipour M. Predictive value of $\mathrm{P}$-wave duration and dispersion in post coronary artery bypass surgery atrial fibrillation. ARYA Atheroscler. 2012;8(2):59-62.

29. Duran A, Ocak T, Talay F, Erkuran MK, Yasar Z, Citisli V, et al. Diagnostic importance of hypocalcemia for pulmonary emboli in the emergency department. SYLWAN. 2014;158(7):366-79. 